\title{
Thermal Model and Analysis for Power Driver Circuit of Brushless DC Motor
}

\author{
Zhigang Gao*, Jun Zhou and Peng Li \\ Institute of Precision Guidance and Control \\ Northwestern Polytechnical University \\ Xi' an, China \\ *Corresponding author
}

\begin{abstract}
To solve the problem of the high temperature of the power driver circuit of BLDCM(Brushless DC Motor) which causes by the tardy heat dissipation, the thermal numerical model was built. The simulation results indicate that the thermal field distribution of the three-phase bridge power driver circuit is relative to the power loss of IGBT(Insulated Gate Bipolar Translator), the distance between heater element and the velocity of air-cooled. By considering the effect factors, the changing curves of max-temperature points are obtained. The researches above could supply the theoretical foundation for optimizing the cooling system design of power driver circuit.
\end{abstract}

Keywords-three-phase bridge power driver circuit; IGBT; thermal numerical model; simulations

\section{INTRODUCTION}

For the superior characteristics of BLDCM, such as large power density, high efficient, it is widely applied to the flight control electrical servo system of aircraft, missiles and rockets. But for the restrict of its volume and weight, and with the large output power, the heat generated during the operation cannot be dissipated in time, which may give rise to the overheating damage and malfunction to the IGBT, and then the motor also cannot function well[1,2].

For the high-power IGBT, its temperature rise caused by power loss will increase when operating with high current, which can lead to the junction temperature rapid rise. The overheating is always the crucial factor for the characteristics of power device, the maximum output power and reliability, the device will be destroyed with the high junction temperature over allowable one[3]. The allowable junction temperature depends on two elements[4]: the self-calorific value of power device and the design of cooling system for power driver circuit, so it is necessary to analyze the heat generating characteristic of power driver circuit for BLDCM and simulate the thermal fields, which can make sure the maximum temperature of IBGT is always under the limit available temperature, then the reliable operation can be realized during the thermal environment.

\section{THERMAL MECHANISM}

The power driver circuit of BLDCM uses the three-phase bridge driver circuit which is consist of six IGBT, the basic structure is shown as Figure I.
In the power driver circuit of BLDCM, the tube core and fly-wheel diode(FWD) inside the IGBT work as high speed switch, and both of them exist the conduction power loss and switching power loss, which dissipate outside as heat $[5,6]$.

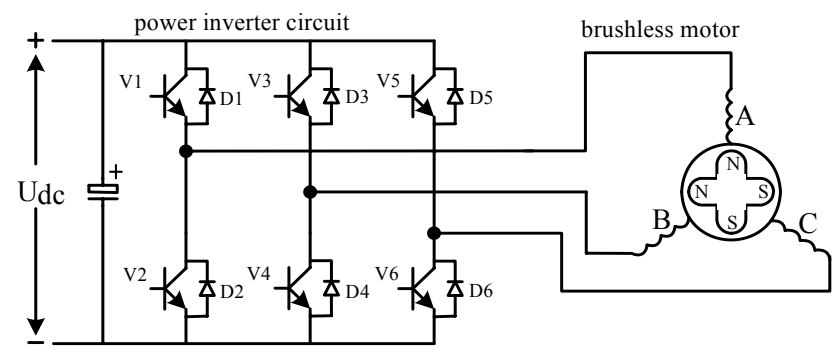

FIGURE I. STRUCTURE OF POWER DRVER CIRCUIT FOR BLDCM

The main source of power loss for IGBT is: the saturation voltage drop $V_{C E(s a t)}$ born from turn on and the switch power consumption $E_{\text {on }}$ and $E_{\text {off }}$ when switching. So the sum power $\operatorname{loss}\left(P_{\text {cond } T r}\right.$ and $\left.P_{S w T r}\right)$ caused by the two reasons above is the total power loss of IGBT.

In the follow current proceed of FWD, there is voltage drop $V_{F}$ of positive onset, meanwhile, in the proceed of reverse recovery, there is the reverse recovery energy consumption $E_{\text {rec }}$. Then $P_{\text {cond } D}$ is the conduction loss resulting form $V_{F}$, and $P_{s w_{-} D}$ is the switching loss due to $E_{\text {rec }}$.

For the BLDCM of Y connection with two-phase On-Off, it can be divided into three-phase and six conditions, the formulas of power loss can be deduced as following:

$$
\left\{\begin{array}{l}
P_{\text {cond_Tr }}=\frac{1}{3} V_{C E(s a t)} \cdot I_{C} \cdot \delta \\
P_{s w_{-} T r}=f_{s w}\left(E_{\text {on }}+E_{\text {off }}\right)\left(\frac{I_{C}}{I_{\text {test }}}\right)\left(\frac{V_{D C}}{V_{\text {test }}}\right) \\
P_{\text {cond_ } D}=\frac{1}{3} V_{F} \cdot I_{C} \cdot(1-\delta) \\
P_{s w_{-} D}=f_{\text {sw }} E_{\text {rec }}\left(\frac{I_{F}}{I_{\text {test }}}\right)\left(\frac{V_{F}}{V_{\text {test }}}\right)
\end{array}\right.
$$


where $\delta$ is the modulation duty cycle of IGBT, $f_{s w}$ is the switching frequency.

So for the single IGBT chip, the total power loss is equal to:

$$
P_{\text {total_IGBT }}=P_{\text {cond_Tr }}+P_{s w_{-} T r}+P_{\text {cond }_{-} D}+P_{\text {sw_ } D}
$$

In the process of thermal simulations, it can be considered as the boundary condition.

\section{THERMAL MOdEL AND SimUlation FOR THREE- BRIDGE POWER DRIVER CIRCUIT}

\section{A. Computation Model}

Supposing that there are six single rectangular IGBT chips, whose type is IRGPS4067DPbF, and the distance between the chips can be adjusted by the conditions of heat dissipation, so the geometry model can be obtained, which is the foundation of the numerical model.

To simplifying the computations, the convective heat transfer coefficient of IGBT chip is considered as the material only for the shell of IGBT chip, which is emerged in the air, and the facture components inner are ignored. The heat generate rate is as the input condition of IGBT heat dissipation, and the heat transfer between layers is neglected.

The size of single IGBT chip is $15.1 \mathrm{~mm} \times 19.8 \mathrm{~mm}$, the surface acts as the heat source. The density of material is $2330 \mathrm{~kg} / \mathrm{m}^{3}$, the specific heat is $0.703 \mathrm{~kJ} / \mathrm{kg} \bullet \mathrm{k}$, and the thermal conductivity is $191 \mathrm{~W} / \mathrm{m} \bullet \mathrm{k}$. The material of top and bottom surface is steel, and the surface is not the heat source, only as convection heat to the surroundings. The side boundary left is the velocity inlet of forced air cooling, and the side boundary right is the free outflow boundary, the computation model is shown as Figure II.

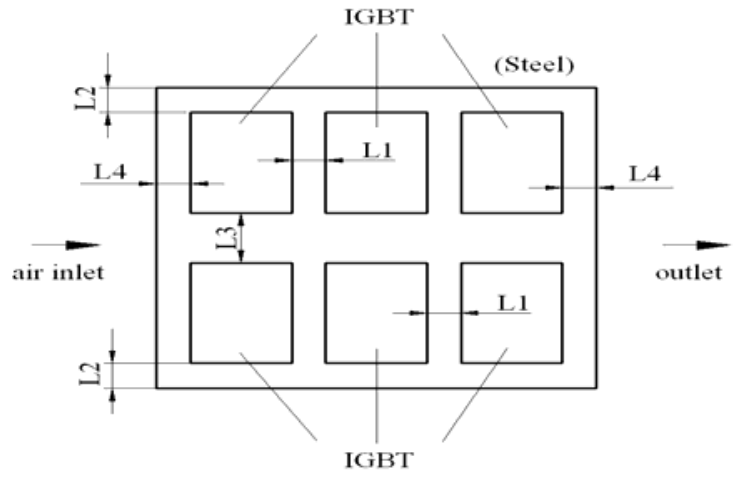

FIGURE II. COMPUTATION MODLE

\section{B. Governing Equations of Thermal Analysis}

The governing equations of air-cooled are as follow:

The mass conservation equation is written as

$$
\frac{\partial \rho}{\partial t}+u \frac{\partial(\rho u)}{\partial x}+v \frac{\partial(\rho v)}{\partial y}+w \frac{\partial(\rho w)}{\partial y}=0
$$

The momentum conservation equation is written as

$$
\frac{\partial \rho \vec{u}}{\partial t}+\nabla \bullet(\rho \vec{u} \vec{u})=-\nabla p-\nabla\left(\frac{2}{3} \rho k\right)+\nabla \bullet \sigma+\vec{F}^{s}+\rho \vec{g}
$$

The energy conservation equation is written as

$$
\frac{\partial \rho U}{\partial t}+\nabla \bullet(\rho \vec{u} U)=-p \nabla \bullet \vec{u}-\nabla \bullet \vec{Q}+\dot{Q}_{l}^{s}+\rho \varepsilon
$$

The turbulent model is standard $\mathrm{k}-\varepsilon$, which is gained by solving by the equations of turbulence energy $\mathrm{k}$ and dissipation rating $\varepsilon$. The equations of $\mathrm{k}$ and $\varepsilon$ are shown as,

$$
\begin{gathered}
\rho \frac{d k}{d t}=\frac{\partial}{\partial x_{i}}\left[\left(\mu+\frac{\mu_{t}}{\varepsilon_{k}} \frac{\partial k}{\partial x_{i}}\right)\right]+G_{k}+G_{b}-\rho \varepsilon-Y_{M} \\
\rho \frac{d \varepsilon}{d t}=\frac{\partial}{\partial x_{i}}\left[\left(\mu+\frac{\mu_{t}}{\varepsilon_{k}} \frac{\partial \varepsilon}{\partial x_{i}}\right)\right]+C_{1 \varepsilon} \frac{\varepsilon}{k}\left(G_{k}+C_{3 \varepsilon} G_{b}\right)-C_{2 \varepsilon} \rho \frac{\varepsilon^{2}}{k}
\end{gathered}
$$

where $G_{k}$ represents the generation of turbulent energy resulting from velocity gradient, $G_{b}$ is the generation of turbulent energy resulting from floating force, $Y_{M}$ represents the effect of total dissipating rate by compressed turbulent pulsating inflation.

The energy governing differential equation of thermal conductivity can be written as

$\frac{\partial}{\partial t}(\rho E)+\nabla \bullet(\overrightarrow{\mathrm{v}}(\rho \mathrm{E}+\mathrm{p}))=\nabla \bullet\left(k_{e f f} \nabla T-\sum h_{j} \vec{J}_{j}+\left(\overline{\bar{\tau}}_{\text {eff }} \bullet \overrightarrow{\mathrm{v}}\right)\right)+\mathrm{S}_{\mathrm{h}}$

where $k_{\text {eff }}$ is the effective thermal conductivity, the first three items on the right represent respectively the thermal conductivity, compositional diffusion and energy transfer causing by viscous diffusion.

The wall-equation is the near-wall model to solve the flow area which is affected by viscosity force. In the area of average velocity, the wall momentum equation is

$$
U^{*}=\frac{1}{\kappa} \ln (\mathrm{Ey} *)
$$

The linear law is applied for the convection energy equation, and the logarithmic law is applied for the turbulent 
area where the turbulent is dominant. Then the wall-law equation is

$$
\begin{aligned}
& T^{*}=\frac{\left(\mathrm{T}_{\omega}-\mathrm{T}_{\mathrm{P}}\right) \rho \mathrm{c}_{\mathrm{p}} C_{\mu}^{1 / 4} k_{P}^{1 / 2}}{\dot{q}} \\
& =\left\{\begin{array}{l}
\operatorname{Pr} y^{*}+\frac{1}{2} \rho \operatorname{Pr} \frac{C_{\mu}^{1 / 4} k_{P}^{1 / 2}}{\dot{q}} U_{P}^{2} \quad\left(\mathrm{y}^{*}<\mathrm{y}_{T}^{*}\right) \\
\operatorname{Pr}_{t}\left[\frac{1}{\kappa} \ln (\mathrm{Ey} *)+\mathrm{P}\right]+ \\
\frac{1}{2} \rho \frac{C_{\mu}^{1 / 4} k_{P}^{1 / 2}}{\dot{q}}\left\{\operatorname{Pr}_{t} U_{P}^{2}+\left(\operatorname{Pr}-\operatorname{Pr}_{t}\right) \mathrm{U}_{c}^{2}\right\}
\end{array} \quad\left(\mathrm{y}^{*}<\mathrm{y}_{\mathrm{T}}^{*}\right)\right.
\end{aligned}
$$

where $\operatorname{Pr}$ is Prandtl number, $\operatorname{Pr}_{t}$ is turbulent Prandtl number.

\section{Results and Analysis}

Assuming that the environment temperature is $25^{\circ} \mathrm{C}$, the distance between IGBT chips is L1, the distance from IGBT chips to the side wall is L2, the line distance between IGBT chips is L3, the distance from air inlet to IGBT chips is L4, then the design conditions are shown as Table I.

TABLE I. COMPUTATION DESIGN CONDITIONS

\begin{tabular}{|c|c|c|c|c|c|c|}
\hline NO. & $\begin{array}{c}\text { Thermal } \\
\text { power }(\mathbf{W})\end{array}$ & $\begin{array}{c}\mathbf{L 1} \\
\mathbf{( m m )}\end{array}$ & $\begin{array}{c}\mathbf{L 2} \\
\mathbf{( m m})\end{array}$ & $\begin{array}{c}\mathbf{L 3} \\
\mathbf{( m m})\end{array}$ & $\begin{array}{c}\mathbf{L 4} \\
\mathbf{( m m})\end{array}$ & $\begin{array}{c}\text { Air } \\
\text { velocity } \\
\mathbf{( m / s )}\end{array}$ \\
\hline I & 15 & 5 & 5 & 10 & 5 & 0.5 \\
\hline II & 50 & 5 & 5 & 10 & 5 & 0.5 \\
\hline III & 100 & 5 & 5 & 10 & 5 & 0.5 \\
\hline IV & 15 & 5 & 5 & 10 & 5 & 0.0 \\
\hline V & 15 & 5 & 5 & 10 & 5 & 0.1 \\
\hline VI & 15 & 5 & 5 & 10 & 5 & 1.0 \\
\hline VII & 15 & 10 & 5 & 10 & 5 & 0.5 \\
\hline VIII & 15 & 15 & 5 & 10 & 5 & 0.5 \\
\hline
\end{tabular}

According to the design conditions, the simulation results of the temperature distribution fields and the maximum temperature change curves are shown as Figure III to Figure IX.

By the Figure III and IV, it can be indicated that with increasing the thermal power of IGBT, under the condition of the same air cooling velocity, high temperature occurs on the large power conditions, but because of the air cooling effect, the temperature difference is not big, comparing with the condition of $15 \mathrm{~W}$ and $100 \mathrm{~W}$, the maximum temperature difference is $18^{\circ} \mathrm{C}$. The highest temperature occurs in the leeside of IGBT, where the air cannot flow fluently and the effect of heat dissipation decreases.

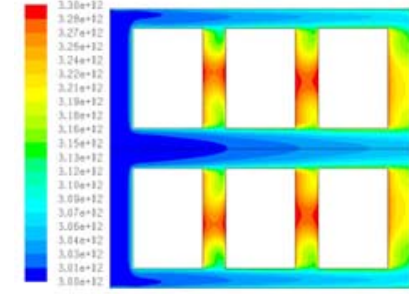

(A) NO.I

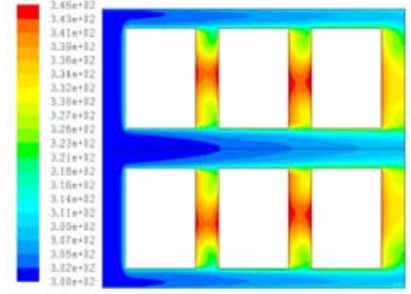

(B) NO.III
FIGURE III. TEMPERATURE DISTRIBUTION COMPARISON OF CONDITION I \& III

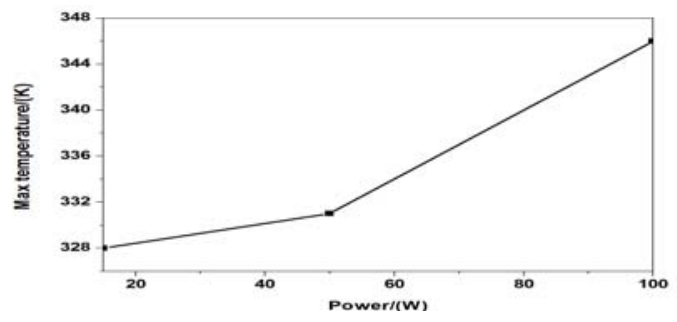

FIGURE IV. MAXIMUM TEMPERATURE - THERMAL POWER(I III)

The Figure V and Figure VI show that comparing with the condition without air cooling, the cooling-air can decrease the working temperature of IGBT obviously. The temperature difference between no air cooling and $1 \mathrm{~m} / \mathrm{s}$ air velocity is $15^{\circ} \mathrm{C}$. With increasing the air velocity, the temperature varies obviously on the windward side, but when the velocity reaches to $0.1 \mathrm{~m} / \mathrm{s}$ and $0.5 \mathrm{~m} / \mathrm{s}$, although the average temperature of latter is lower, the difference of maximum temperature is small.

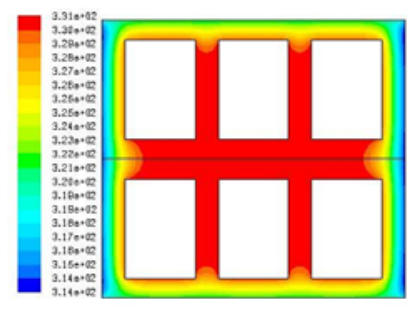

(A) NO.IV

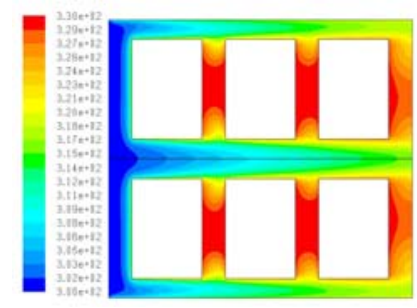

(B) NO.V

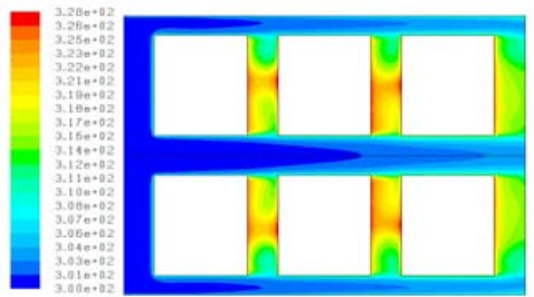

(C) NO.VI

FIGURE V. TEMPERATURE DISTRIBUTION COMPARISON OF CONDITION IV, V \& VI 


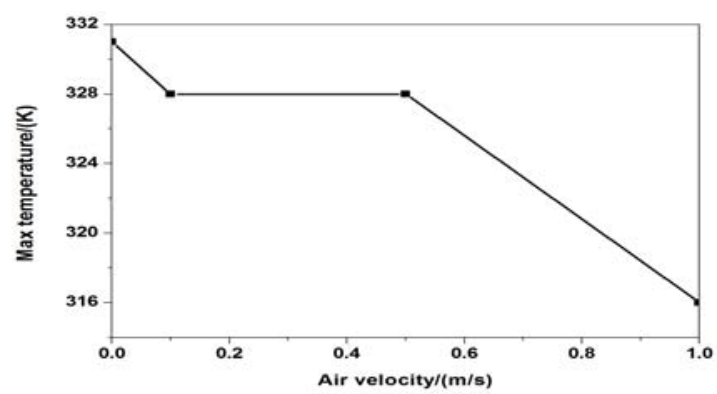

FIGURE VI. MAXIMUM TEMPERATURE - AIR VELOCITY(I,IV,V,VI)

By Figure VII to Figure IX it can be indicated that the larger distance between IGBT chips is conducive for heat dissipation. The largest temperature difference between condition I and VIII is $21^{\circ} \mathrm{C}$. Because of the flow characteristic of air, the cooling effect of front-side is better than the behind. Yet when the distance between IGBT increases to a certain value, although the average temperature decrease, the variation of maximum temperature is not obviously. By the path line figure(Figure VIII), it can be deduced that with increasing the distance, more gas flows into the gap, and there is some eddy flow, which can enforce the heat transfer. But in the last gap of the third IGBT, there is less gas flowing into, so the cooling effect is not good, and the maximum temperature occurs here.

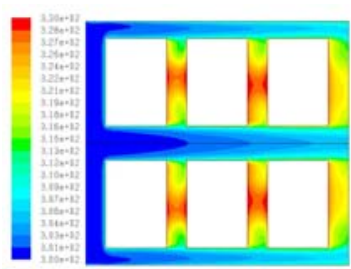

(A) NO.I

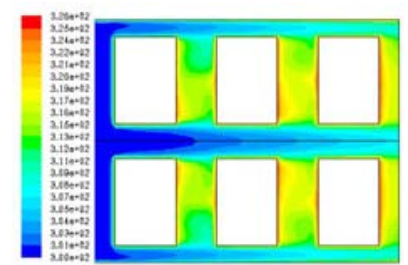

(B) NO.VII

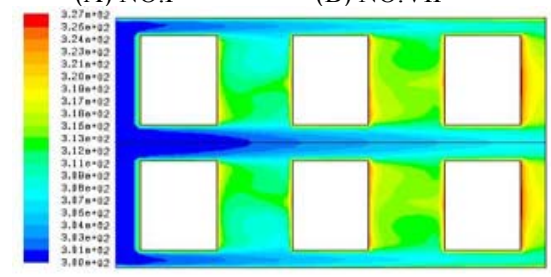

(C) NO.VIII

FIGURE VII. TEMPERATURE DISTRIBUTION COMPARISON OF CONDITION I, VII \& VIII

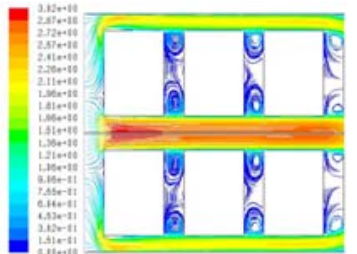

(A) NO.I

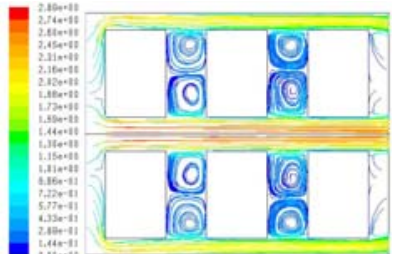

(B) NO.VII

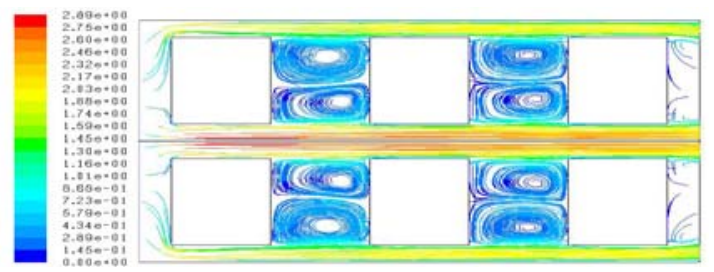

(C) NO.VIII

FIGURE VIII. VELOCITY PATHLINE COMPARISON OF CONDITION I, VII \& VIII

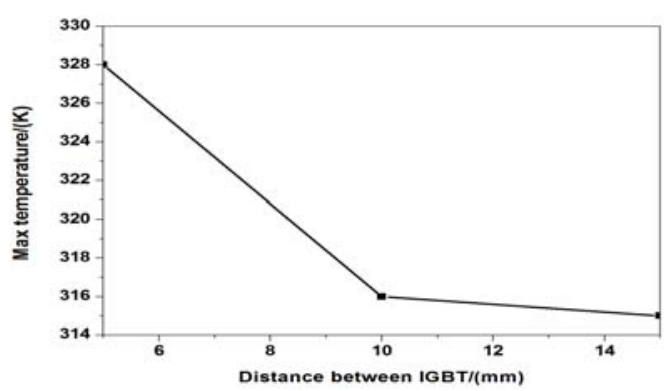

FIGURE IX. MAXIMUM TEMPERATURE - DISTANCE BETWEEN IGBT (I, VII \& VIII)

TABLE II. AVERAGE TEMPERATURE OF IGBT BETWEEN DIFFERENT DISTANCE

\begin{tabular}{|c|c|c|c|}
\hline \multirow{2}{*}{$\begin{array}{c}\text { Distance } \\
(\mathbf{m m})\end{array}$} & \multicolumn{3}{|c|}{ Average temperature-right side (K) } \\
\cline { 2 - 4 } & IGBT(left) & IGBT(middle) & IGBT(right) \\
\hline $5 \mathrm{~mm}$ & 320 & 325 & 322 \\
\hline $10 \mathrm{~mm}$ & 310 & 319 & 321 \\
\hline $15 \mathrm{~mm}$ & 308 & 311 & 317 \\
\hline
\end{tabular}

From the values in Table II, it can be found that with the larger distance, the average temperature deceases obviously from left to right. Under the condition of smaller distance, the air flow is restricted, so the temperature keeps almost steady. And near the outlet boundary, the effect of cooling is also poor because the flow is forced by pressure and most of air flows through the outlet.

\section{CONCLUSIONS}

According to the structure and working principle of IGBT, which is the component of three-phase bridge power driver circuit for BLDCM, the numerical thermal model is built. By the model, the heating environment can be simulated exactly. The conclusions can be obtained as following:

(1) The numerical model is built by the working principle of power driver circuit for BLDCM, and the heating power is also analyzed, so the model can be considered as the theoretical basis for optimizing the cooling design.

(2) The heating power, air cooling velocity and the overall arrangement of IGBT have great influence for the thermal field, which cannot be ignored in the process of optimizing design. With the larger heating power, the higher temperature can be gotten. When increasing the air velocity, the better heat dissipation can be obtained. And the larger distance between IGBT is helpful to decrease the temperature, which is obviously in the condition with larger distance. 
(3) For the air-cooled system of one-side, the air can decrease the surface temperature effectively only for windward side, for the leeside, the effect of these crucial factors reduce. So in the course of optimizing the system, the two-side air cooling can be tried. But then for the mutual interference of the air flow from opposite directions, the location layout becomes the most critical factor.

\section{REFERENCES}

[1] Xia Changliang, Control System of Brushless DC Motor, Beijing: Science Press, 2009.

[2] Wu Hongkui, Basis and Application of IGBT, Beijing: Science Press, 2010.

[3] Li Hong, MOSFET, IGBT Dirven Integrated Circuit and Application. Beijing: Science Press, 2013.

[4] Hu Jianhui, Li Jingeng and Zou Jibin, "Losses calculation of IGBT module and heat dissipation system," Transaction of China Electrotechnical Society, vol. 24, pp.159-163, March 2009.

[5] Du Yi, Liao Meiying, "Losses caculation of IGBT module and dissipation system design inverters," Electrical Drive Automation, vol.33, pp.42-46, February 2011.

[6] Xie Qinlan, Chen Hong, "Losses caculating of IGBT's in PWM inverters," Journal of South Certral University for Nationalities, vol.22, pp.39-41, March 2003.

[7] Fu Guicui, Gao Zexi and Zou Hang, "Thermal design and power component and optimal design of heat sink," Semiconductor Technology, vol.29. pp.78-81, May 2004.

[8] Li Ming, "A study on IGBT characteristic diagram," Electrical Welding Machine, vol.30, November 2000.

[9] Zheng Jun, Wang Xiaobao and Guan Yanxia, "Research on heat transfer in the high power IGBT module based on ANSYS," Power Electronic, vol.45, January 2011.

[10] $\mathrm{Wu}$ Yansong, "Research on electro-thermal model for junction temperature prediction in IGBT modules," Advanced Technology of Electrical Engineering and Energy, vol.33, March 2014. 